\title{
AVALIAÇÃO ERITROCITÁRIA E BIOQUÍMICA DE JUNDIÁS (Rhamdia quelen) SUBMETIDOS À DIETA COM DIFERENTES NÍVEIS PROTÉICOS E ENERGÉTICOS
}

\author{
Leticia Hayashi Higuchi, ${ }^{1}$ Aldi Feiden, ${ }^{2}$ Márcia Luzia Ferrarezi Maluf, ${ }^{2}$ \\ Jackeline Marcante Dallagnol, ${ }^{2}$ Micheli Zaminhan ${ }^{2}$ e Wilson Rogério Boscolo ${ }^{2}$
}

1. Universidade Estadual do Oeste do Paraná, Unioeste. E-mail: biologaleticiahh@hotmail.com

2. Universidade Estadual do Oeste do Paraná, Unioeste

\section{RESUMO}

Objetivou-se com este trabalho avaliar o efeito de diferentes rações sobre os parâmetros eritrocitários (hemácias, hemoglobina e hematócrito) e bioquímicos (glicose, albumina e proteína) de jundiás (Rhamdia quelen). Utilizaram-se 36 jundiás (comprimento médio $=32 \pm 11 \mathrm{~cm}$ e peso médio $=442 \pm 46 \mathrm{~g}$ ), provenientes de tanques-rede localizados no município de Santa Helena, PR. Foram testados seis tratamentos com diferentes níveis proteicos $-25 \%$, $30 \%$ e $35 \%$ - e dois níveis de energia digestível 3.250 e 3.500 kcal. Os valores médios obtidos para hemácias $\left(10^{6} / \mu \mathrm{L}\right)$ foram de $1,98 \pm 2,21$, hemoglobina ( $\mathrm{g} / \mathrm{dL}) 8,33 \pm 10,50$ e hematócrito (\%) $35,00 \pm 47,00$. Os parâmetros bioquímicos para glicose $(\mathrm{mg} / \mathrm{dL})$, proteína $(\mathrm{mg} / \mathrm{mL})$ e albumina $(\mathrm{g} / \mathrm{dL})$ foram $75,92 \pm 124,30 ; 5,78$ $\pm 6,92$ e $3,33 \pm 4,42$, respectivamente. Os resultados obtidos neste trabalho demonstraram que não houve diferença $(\mathrm{P}>0,05)$ entre os parâmetros eritrocitários e bioquímicos em relação aos níveis de proteína e energia analisados.

PALAVRAS-CHAVES: Hematologia, Rhamdia quelen, tanques-rede, dietas.

\section{ERYTHROCITARY AND BIOCHEMICAL EVALUATION OF RHAMDIA QUELEN SUBMITTED TO DIETS WITH DIFFERENT PROTEIC AND ENERGETIC LEVELS}

The aim of the study was to evaluate the effect of different diets on erythrocitary (erythrocytes, hemoglobin and hematrocit) and biochemical (glucose, albumin and protein) parameters of Rhamdia quelen fish. A total for 36 Rhamdia quelen fish (mean length $=32 \pm$ $11 \mathrm{~cm}$ and mean weight $=442 \pm 46 \mathrm{~g}$ ), from net cages located in Santa Helena, Paraná, Brazil were used. Six treatments with different protein levels $(25,30$ and $35 \%)$ and two digestible energy levels (3250 and

KEYWORDS: Cages, Hematology, Rhamdia quelen, diets.

\section{INTRODUÇÃO}

Na criação de peixes, quanto maior for a quantidade de ração, melhores serão o aproveitamento do
$3500 \mathrm{kcal})$ were tested. The mean values obtained were $1.98 \pm 2.21$ for erythrocytes $\left(10^{6} / \mu \mathrm{L}\right), 8.33 \pm 10.50$ for hemoglobin $(\mathrm{g} / \mathrm{dL})$, and $35.00 \pm 47.00$ for hematrocit $(\%)$. The biochemical parameters for glucose $(\mathrm{mg} / \mathrm{dL})$, protein $(\mathrm{mg} / \mathrm{mL})$ and albumin $(\mathrm{g} / \mathrm{dL})$ were $75.92 \pm$ $124.30,5.78 \pm 6.92$ and $3.33 \pm 4.42$, respectively. The results obtained showed no difference $(\mathrm{P}>0.05)$ between erythrocitary and biochemical parameters regarding the protein and energy levels analyzed.

alimento e a taxa de crescimento dos animais. Para que isso ocorra, a dieta deve possuir energético e proteico, conter os aminoácidos necessários e os níveis adequados, além de ter boa digestibilidade (PASTORE, 1999). 
Adeterminação das exigências de proteína e energia é essencial para o cultivo de qualquer espécie, pois a proteína é o principal nutriente na dieta dos peixes, representando o maior custo econômico no cultivo intensivo. Já a energia é, quantativamente, o componente mais importante da dieta, uma vez que geralmente animais monogástricos comem para satisfazer primeiramente suas exigências energéticas, sendo que quanto maior for a energia na dieta menor tenderá a ser seu consumo (NG et al., 1998).

Ao se formular uma dieta, deve-se buscar o balanço nutricional dos nutrientes para suprir o crescimento e a sanidade dos animais, mas, também, deve-se processá-la para que tenha propriedades físicas desejáveis (NRC, 1993).

O jundiá (Rhamdia quelen) é um siluriforme de hábito onívoro, encontrado desde o sul do México até a Argentina (LAZZARI et al., 2006). Também conhecido como bagre do sul americano (TAVARES-DIAS et al., 2002), esse teleósteo apresenta carne saborosa e bem aceita pelos consumidores, o que leva à sua grande importância comercial .

A hematologia vem se tornando um precioso instrumento no conhecimento das alterações fisiológicas que ocorrem nos peixes, Essas alterações são causadas, principalmente, por fatores internos como sexo, maturação gonodal, idade, modo de vida e pelas mudanças em fatores deágua, como teor de oxigênio dissolvido, temperatura, $\mathrm{pH}$ e condutividade elétrica (RANZANI-PAIVA et al., 2004).

A simplicidade da maioria das técnicas de amostragem de sangue é, provavelmente, responsável pelo crescente aumento do uso da hematologia como meio de se estabelecer o estado de saúde dos peixes. Esse tipo de análise é importante tanto na avaliação da resistência quanto na avaliação nutricional dos peixes (RANZANI-PAIVA, 2005).

Objetivou-se, neste trabalho, avaliar os parâmetros eritrocitários do jundiá (Rhamdia quelen - P $i$ melodidae), com diferentes rações, determinando-se o número de hemácias, hematócrito, taxa de hemoglobina e parâmetros bioquímicos por meio da dosagem de proteína, albumina e glicose.

\section{MATERIAL E MÉTODOS}

Peixes e características de criação

A coleta de sangue foi realizada na Unidade Demonstrativa de Aquicultura: tanques-rede para cultivos experimentais e demonstrativos, no Reservatório de Itaipu, município de Santa Helena, PR, Brasil. As análises hematológicas e bioquímicas foram realizadas no Laboratório de Microbiologia da Unioeste, Câmpus, Toledo, PR.

Esse experimento iniciou-se em janeiro de 2006. Os animais foram acondicionados em tanques-redes $\left(5 \mathrm{~m}^{3}\right)$, com estocagem em densidade de 80 indivíduos/ $\mathrm{m}^{3}$, e alimentados duas vezes por dia. Os peixes foram alimentados com seis rações experimentais com diferentes níveis de proteína $25 \%, 30 \%$ e $35 \%$, respectivamente, e dois níveis de energia digestível 3.250 e $3.500 \mathrm{kcal}$. (Tabela 1). Após sete meses de alimentação foi realizada a coleta de sangue para as análises hematológicas e bioquímicas. Foram utilizados 36 jundiás provenientes de tanques de cultivo, com comprimento padrão médio \pm desvio-padrão de $32 \pm 11 \mathrm{~cm}$ e peso médio de $442 \pm 46 \mathrm{~g}$.

\section{Coleta de sangue}

Os peixes foram capturados, anestesiados com benzocaína $75 \mathrm{mg} / \mathrm{L}$ como preconizam GOMES et al. (2001), e, em seguida, foi coletado o sangue $(2,0 \mathrm{~mL})$ por punção caudal com auxílio de seringa. As amostras destinaram-se à avaliação hematológica utilizando-se sangue total colhido com anticoagulante EDTA (10\%) e análise bioquímica de soro e plasma.

Avaliação dos parâmetros hematológicos

O hematócrito foi determinado segundo o método de GOLDENFARB et al. (1971), a taxa de hemoglobina de acordo com, e a contagem do número de eritrócitos em câmara de Neubauer sob microscópio óptico com objetiva de quarenta vezes, após diluição do sangue total com líquido de Hayem (COLLIER, 1944).

Avaliação dos parâmetros bioquímicos

Nas análises bioquímicas utilizaram-se soro, para dosagem de proteínas totais e albumina, e plasma, para dosagem da glicose. Para se obterem o plasma (colheu-se com fluoreto) e o soro (sem anticoagulante), as amostras foram centrifugadas a $2.500 \mathrm{rpm}$, por cinco minutos, e congeladas a $-20^{\circ} \mathrm{C}$, para determinação das análises.

As análises foram realizadas com o uso de kits específicos Gold Analisa Diagnóstica ${ }^{\circledR}$ e conforme as instruções do fabricante, sendo feita leitura em espectrofotômetro. 
TABELA 1. Composição percentual e química das rações experimentais com diferentes níveis de proteína e energia (matéria natural)

\begin{tabular}{|c|c|c|c|c|c|c|}
\hline \multirow{4}{*}{ Ingredientes (\%) } & \multicolumn{6}{|c|}{ Níveis de energia $\mathrm{kcal} / \mathrm{kg}$} \\
\hline & \multicolumn{3}{|c|}{3.250} & \multicolumn{3}{|c|}{3.500} \\
\hline & \multicolumn{6}{|c|}{ Níveis de proteína (\%) } \\
\hline & 25 & 30 & 35 & 25 & 30 & 35 \\
\hline Arroz quirera & 30,000 & 30,000 & 30,000 & 30,000 & 30,000 & 30,000 \\
\hline Antioxidante (BHT) & 0,030 & 0,030 & 0,030 & 0,030 & 0,030 & 0,030 \\
\hline Calcário calcítico & 0,027 & 0,107 & 0,188 & 0,000 & 0,081 & 0,161 \\
\hline Farinha de carne e ossos & 4,787 & 4,787 & 4,787 & 4,787 & 4,787 & 4,787 \\
\hline Fosfato bicálcico & 0,496 & 0,249 & 0,002 & 0,536 & 0,290 & 0,043 \\
\hline Farinha de peixe & 3,334 & 3,334 & 3,334 & 3,334 & 3,334 & 3,334 \\
\hline Farinha de vísceras de aves & 15,000 & 15,000 & 15,000 & 15,000 & 15,000 & 15,000 \\
\hline Farelo de soja & 14,379 & 27,215 & 40,051 & 15,390 & 28,225 & 41,061 \\
\hline Milho & 30,673 & 18,146 & 5,618 & 25,057 & 12,528 & 0,001 \\
\hline Óleo de soja & 0,323 & 0,182 & 0,041 & 4,916 & 4,775 & 4,633 \\
\hline Suplemento min. vitam. ${ }^{1}$ & 0,400 & 0,400 & 0,400 & 0,400 & 0,400 & 0,400 \\
\hline Antifúngico & 0,050 & 0,050 & 0,050 & 0,050 & 0,050 & 0,050 \\
\hline Sal comum & 0,50 & 0,50 & 0,50 & 0,50 & 0,50 & 0,50 \\
\hline Total & 100,00 & 100,00 & 100,00 & 100,00 & 100,00 & 100,00 \\
\hline Nutrientes (\%) & \multicolumn{6}{|c|}{ Valores calculados } \\
\hline Amido & 41,010 & 33,205 & 25,400 & 37,511 & 29,705 & 21,901 \\
\hline Cálcio & 1,450 & 1,450 & 1,450 & 1,450 & 1,450 & 1,450 \\
\hline Energia bruta & 4060 & 4079 & 4098 & 4318 & 4338 & 4357 \\
\hline Energia digestível (kcal/kg) & 3250 & 3250 & 3250 & 3500 & 3500 & 3500 \\
\hline Fibra bruta & 1,923 & 2,442 & 2,961 & 1,875 & 2,394 & 2,913 \\
\hline Fósforo total & 1,000 & 1,000 & 1,000 & 1,000 & 1,000 & 1,000 \\
\hline Gordura & 4,279 & 3,879 & 3,479 & 8,645 & 8,245 & 7,845 \\
\hline Linoleico & 1,242 & 1,019 & 0,796 & 3,623 & 3,399 & 3,176 \\
\hline Lisina & 1,281 & 1,606 & 1,932 & 1,295 & 1,620 & 1,946 \\
\hline Metionina + Cistina & 0,905 & 1,021 & 1,138 & 0,897 & 1,013 & 1,130 \\
\hline Metionina & 0,455 & 0,517 & 0,579 & 0,452 & 0,514 & 0,576 \\
\hline Proteína bruta & 25,000 & 30,000 & 35,000 & 25,000 & 30,000 & 35,000 \\
\hline
\end{tabular}

${ }^{1} \mathrm{O}$ suplemento mineral e vitamínico deve ser completo para peixes em tanques-rede com composição mínima por kg de ração de Mn $15 \mathrm{mg}$, Zn $70 \mathrm{mg}$, Fe 75 mg, Cu 8 mg, Co 0,1 mg, I 1 mg, Se 0,2 mg, Vit A 5000 UI, Vit D 2000 UI, Vit E 80 mg, Vit K 10 mg, Vit B 15 mg, Vit B 15 mg, Vit B 15 mg, Vit $B_{12} 15 \mathrm{mg}$, Vit C $250 \mathrm{mg}$, Ác. fólico $5 \mathrm{mg}$, Ác. pantotênico $40 \mathrm{mg}$, Niacina $70 \mathrm{mg}$, Colina $700 \mathrm{mg} / \mathrm{kg}$, Biotina 0,5 mg/kg.

Análise estatística

Os dados obtidos foram submetidos à análise de variância a 5\% de probabilidade, através do programa estatístico (SAEG) Sistema de Análise Estatísticas e Genéticas, desenvolvido na Universidade Federal de Viçosa (UNIVERSIDADE..., 1997).
Resultados e Discussão

Na avaliação do desempenho dos jundiás observaram-se diferenças significativas entre os tratamentos no ganho médio de peso final. Quanto às variáveis eritrocitárias, os resultados demonstraram que não houve diferenças significativas $(\mathrm{P}>0,05)$ em comparação com diferentes níveis de proteínas e energia (Tabela 2). 
TABELA 2. Variáveis hematológicas de jundiás (Rhamdia quelen) submetidos a dieta com diferentes níveis proteicos e energéticos

\begin{tabular}{|c|c|c|c|c|c|c|c|}
\hline \multirow{4}{*}{ Parâmetros* } & \multicolumn{6}{|c|}{ Níveis de Energia digestível (kcal/kg) } & \multirow[b]{4}{*}{ C.V. $(\%)$} \\
\hline & \multicolumn{3}{|c|}{3250} & \multirow{2}{*}{\multicolumn{3}{|c|}{3500}} & \\
\hline & \multicolumn{3}{|c|}{ Níveis de Proteína (\%) } & & & & \\
\hline & 25 & 30 & 35 & 25 & 30 & 35 & \\
\hline Eritrócitos $\left(\mathrm{x} 10 / \mu \mathrm{L}^{6}\right)$ & 2,12 & 2,16 & 1,98 & 2,21 & 2,14 & 2,11 & $9,74^{\mathrm{NS}}$ \\
\hline Hemoglobina (g/dL) & 9,66 & 10,04 & 8,33 & 9,11 & 10,50 & 9,02 & $28,06^{\mathrm{NS}}$ \\
\hline Hematócrito (\%) & 40,87 & 35,00 & 47,00 & 38,75 & 40,50 & 41,17 & $18,08^{\mathrm{NS}}$ \\
\hline
\end{tabular}

* Médias na mesma linha seguidas de letra distintas diferem $(\mathrm{P}<0,05)$ pelo teste de Duncan.

Os resultados para peso médio final (PMF) foram: $334,0 \pm 31,8^{\text {bx }} ; 445,9 \pm 37,8^{\text {ax }} ; 479,8 \pm 26,7^{\text {ax }}$; $334,8 \pm 10,8^{\mathrm{bx}} ; 470,1 \pm 21,4^{\mathrm{ax}} ; 482,5 \pm 18,7^{\mathrm{ax}}, \mathrm{em}$ que $\mathrm{x}$ e y diferem para o fator de ED e $\underline{\mathrm{a}}$ e $\underline{\mathrm{b}}$ para o fator de proteína.

No presente estudo, os peixes alimentados com o nível $25 \%$ de PB apresentaram menor peso em relação aos dos níveis de $30 \%$ e $35 \%$ de PB. Já os níveis de ED não ocasionaram alterações no peso médio final dos peixes. Salienta-se que as variáveis hematológicas são dados essenciais para avaliar o estado de saúde dos animais, principalmente se existe anemia, definida como a presença de eritrócitos, concentração de hemoglobina e/ou hematócrito abaixo dos valores normais de referência (LOPES et al., 2007). Os resultados deste estudo demonstraram que os níveis de proteína e de energia utilizados na dieta não acarretaram alterações nas variáveis eritrocitárias.

Os valores médios de eritrócitos oscilaram de 1,98 a $2,21 \times 10 / \mu \mathrm{L}^{6}$ entre os diferentes tratamentos. Nos peixes, os eritrócitos são ovais e têm núcleo central acompanhando o formato da célula, com cromatina compactada e sem nucléolos. Os eritrócitos contêm o pigmento respiratório, a hemoglobina que tem por função transportar $\mathrm{o}_{2} \mathrm{e}$ parte do $\mathrm{CO}_{2}$ no sangue. Qualquer deficiência no eritrócito será traduzida como uma falta de $\mathrm{O}_{2}$ nos tecidos (RANZANI et al., 2004).

O hematócrito corresponde ao volume ocupado pelos eritrócitos contidos numa certa quantidade de sangue total, sendo que valores baixos podem indicar anemia. Neste ensaio, os valores variaram de $35 \%$ a $47 \%$. Valores superiores foram observados por TAVARES-DIAS et al. (2002) para Rhamdia quelen (peso 44,0 g) quando encontraram 1,90; 6,7 e $26 \%$ de eritrócitos, hemoglobina e hematócrito, respectivamente. É possível que esse aumento esteja relacionado com o tamanho do peixe, o que pode interferir no quadro hematológico.

Os resultados evidenciaram que não houve diferença significativa $(\mathrm{P}>0,05)$ para parâmetros bioquímicos (Tabela 3 ) entre diferentes rações testadas.

TABELA 3. Parâmetros bioquímicos de jundiás (Rhamdia quelen) submetidos a dieta com diferentes níveis proteicos e energéticos

\begin{tabular}{|c|c|c|c|c|c|c|c|}
\hline \multirow{4}{*}{ Parâmetros* } & \multicolumn{6}{|c|}{ Níveis de energia digestível (kcal/kg) } & \multirow[b]{4}{*}{$\mathrm{CV}(\%)$} \\
\hline & \multicolumn{3}{|c|}{3.250} & \multicolumn{3}{|c|}{3.500} & \\
\hline & \multicolumn{6}{|c|}{ Níveis de proteína (\%) } & \\
\hline & 25 & 30 & 35 & 25 & 30 & 35 & \\
\hline Glicose (mg/dL) & 94,35 & 75,92 & 124,30 & 104,40 & 93,83 & 92,73 & $31,56^{\mathrm{NS}}$ \\
\hline Albumina $(\mathrm{g} / \mathrm{dL})$ & 3,87 & 4,42 & 3,33 & 3,56 & 3,32 & 4,36 & $18,30^{\mathrm{NS}}$ \\
\hline Proteína ${ }^{* *}(\mathrm{mg} / \mathrm{mL})$ & 6,11 & 6,92 & 6,37 & 6,70 & 5,78 & 6,32 & $24,03^{\mathrm{NS}}$ \\
\hline
\end{tabular}

* Médias na mesma linha seguidas de letras distintas diferem $(\mathrm{P}<0,05)$ pelo teste de Duncan.

** Proteína plasmática total. 
Para os parâmetros bioquímicos foram encontrados valores médios e amplitude de variação, sendo para glicose $97,58 \mathrm{mg} / \mathrm{dL}$ e 75,92 a $124,30 \mathrm{mg} / \mathrm{dL}$; para proteína total $6,37 \mathrm{mg} / \mathrm{mL}$ e 5,78 a 6,92 ; e para albumina $3,81 \mathrm{~g} / \mathrm{dL}$ e 3,33 a 4,42. A glicose está relacionada a uma série de agentes estressores, entre eles, a variação de temperatura, o manuseio e o transporte, segundo URBINATI et al. (2004). Dessa forma, ela é empregada como indicador de distúrbio fisiológico, por ser a principal fonte de energia utilizada pelos peixes para suportar situações adversas (MORGAN \& IWAMA, 1997).

TAVARES-DIAS \& MATAQUEIRO (2004) encontraram valores para a glicose de $63,0 \pm 8,1 \mathrm{mg} /$ dL em espécies da família Characidae. Esses valores são similares aos apresentados neste trabalho e superiores aos obtidos para tambaquis (Colossoma macropomum) - 116,7 mg/dL - por TAVARES-DIAS \& MATAQUEIRO (2004). Os resultados evidenciaram que não houve diferença significativa $(\mathrm{P}>0,05)$ para parâmetros bioquímicos (Tabela 3 ) entre as diferentes rações testadas.

A concentração de proteína plasmática estárelacionada com o metabolismo proteico e com as condições nutricionais (COLES, 1984), pois sua deficiência na alimentação pode ocasionar anemias. Neste estudo, os valores oscilaram entre $6,92 \mathrm{e} 5,78 \mathrm{~g} / \mathrm{dL}$. Ao analisar juvenis de pacu (Piaractus mesopotamicus) submetidos a diferentes níveis de vitamina E, SADO (2008) observou alterações significativas para os valores de proteínas plasmáticas, que variaram de 4,6 a 5,5 g/dL.

A composição bioquímica do plasma sanguíneo demonstra a situação metabólica dos tecidos animais. Por meio delas é possível detectar alterações no funcionamento dos órgãos e a adaptação do animal diante dos desafios nutricionais, fisiológicos e desequilíbrios metabólicos, específicos ou de origem nutricional. Entretanto, para uma melhor interpretação, são necessários valores de referência apropriados à população e à região a serem analisadas (GONZÁLEZ \& SCHEFFER, 2003).

Outros fatores como estado nutricional, sazonalidade, maturação gonadal, sexo e variação genética também podem influenciar significativamente as variáveis hematológicas (KORI-SIAKPERE, 1985). Ainda podem-se considerar as diferenças entre as espécies, pois indivíduos de tamanhos ditintos liberam energia em quantidades variadas, de acordo com seu tamanho corporal, o que pode interferir no quadro hematológico (TAVARES-DIAS et al., 2002).

\section{CONCLUSÕES}

Os resultados obtidos neste trabalho demonstram que não houve diferenças entre os parâmetros hematológicos e bioquímicos em relação aos níveis de proteína e de energia.

Ainda são necessários mais estudos sobre nutrição animal, alimentação, saúde (hematologia e bioquímica), fisiologia e comportamento reprodutivo.

\section{REFERÊNCIAS}

COLES, E. H., Função hepática. In: COLES E. H. (Ed.). Patologia clínica veterinária. São Paulo: Manole, 1984. p. 185-219.

COLLIER, H. B. The standardization of blood haemoglobin determinations. Canadian Medical Association Journal, v. 50, p. 550-552, jun. 1944.

GOLDENFARB, P. B.; BOWYER, F. P.; HALL, E.; BROSIOUS, E. Reproducibility in the hematology laboratory: the microhematocrit determination. American Journal of Clinical Pathology. v. 56, n. 1, p.35-39, jul. 1971.

GOMES, L. C.; CHIPPARI-GOMES, A. R.; LOPES, N. P.; ROUBACH, R.; ARAUJO-LIMA, C. A. R. M. Efficacy of benzocaine as an anesthetic in juvenile tambaqui Colossoma macropomum. Jounal of the World Aquaculture Society, v. 32, n. 4, p. 426-431, 2001.

GONZÁLEZ, F. H. D.; SCHEFFER, J. F. S. Perfil sangüíneo: ferramenta de análise clínica, metabólica e nutricional. In: GONZÁLEZ, F. H. D. ; CAMPOS, R. (Eds.). Anais do I Simpósio de Patologia Clínica Veterinária da Região Sul do Brasil. Porto Alegre: UFRGS, 2003. p. 73- 89. Disponível em: < http://www.lume.ufrgs.br/bitstream/handle/10183/13177/000386508.pdf? sequence=1>. Acesso em: 28 jan. 2010.

KORI-SIAKPERE, O. Haematological characteristics of Clarias isheriensis Sydenham. Journal of Fish Biology, v. 27, p. 259-263, 1985.

LAZZARI, R.; RADÜNZ NETO, J.; EMANUELLI, T. ; PEDRON, F. A.; COSTA, M. L.; LOSEKANN, M. E.; CORRÊIA, V.; BOCHI,V.C. Diferentes fontes protéicas para a alimentação do jundiá (Rhamdia quelen). Ciência Rural, v. 36, n. 1, p. 240-246, 2006.

LOPES, S. T. A.; BIONDO, A. W.; SANTOS, A. P. Manual de patologia clínica veterinária. 3. ed.Santa Maria: UFSM, 2007. 107 p. 
MORGAN, J. D.; IWAMA, G. K. Measurements of stressed states in the field. In: IWAMA, G. K.; PICKERING, A. D.: SUMPTER, J. P. SCHRECK, C. B. Fish stress and health in aquaculture. Cambridge: Cambridge University Press, 1997.

NG, W.; KEENBIYEHETTY, C. N.; WILSON, R. P. Bioavilability of niacin from feed ingredients commonly used in feeds for channel catfish, Ictalurus punctatus. Aquaculture, v. 161, n. 1-4. p. 391-402, 1998.

NRC - National Research Council. Nutrient requeriments of fish. Washington: National Academy Press, 1993.

PASTORE, S. A dose certa. Alimentação Animal, n. 15, jul.-ago. 1999. Disponível em: <http://www.bichoonline.com.br/artigos/ aa0006htm>. Acesso em: 20 out. 2006.

RANZANI-PAIVA, M. J. T.; TAKEMOTO, R. M.; LIZAMA, M. A. P. Sanidade de organismos aquáticos. In. RANZANI-PAIVA, M. J. T.; SILVA-SOUZA, A.T., Hematologia de peixes brasileiros. São Paulo: Varela, 2004.

RANZANI-PAIVA, M. J. T. Técnicas hematológicas e pesquisa de hemoparasitos: hematologia de peixes. São Paulo: Instituto de Pesca, 2005.
SADO, R. Y. Imunoestimulantes dietéticos e respostas biológicas, bioquímicas e hematológicas de juvenis de Piaractus mesopotamicus (Holmberg, 1887). 2008. 137f. Tese (Doutorado) - Universidade de São Paulo, Escola Superior de Agricultura Luiz de Queiroz, Piracicaba, 2008. Disponível em: <http://www.teses. usp.br/teses/disponiveis/11/11139/tde-11022009-091806/pt-br. php>. Acesso em: 28 jan. 2010.

TAVARES-DIAS, M.; MATAQUEIRO, M. J. Características hematológicas e bioquímicas de Piaractus mesopotamicus Holmberg, 1887 (Osteichthyes: Characidae) oriundos de cultivo intensivo. Acta Scientiarum. Biological Sciences, v. 26, n. 2, p. 157-162, 2004.

TAVARES-DIAS, M.; MELO, J. F. B.; MORAES, G.; MORAES, F. R. Características hematológicas de Teleósteo Brasileiro. IV. Variáveis do jundiá Rhamdia quelen (PIMELODIDAE). Ciência Rural, v. 32, n. 4, p. 693-698, 2002.

UNIVERSIDADE FEDERAL DE VIÇOSA. SAEG: Sistema para Análises Estatísticas e Genéticas. Versão 7.1 Viçosa, UFV. 1997. 150 p. (Manual de usuário).

URBINATI, E. C.; ABREU, J.; CAMARGO, A.; PARRA, M. Loading and transport stress in juvenile matrinxã (Brycon cephalus) at various densities. Aquaculture, v. 229, p. 389-400, 2004.

Protocoladodo em: 09 mar. 2010. Aceito em: 28 jan. 2011. 